\title{
The PI3K/Akt pathway mediates the expression of type I collagen induced by TGF- $\beta 2$ in human retinal pigment epithelial cells
}

\author{
Katsuhiko Yokoyama • Kenichi Kimoto • Yuji Itoh • \\ Kazuo Nakatsuka • Noritaka Matsuo • \\ Hidekatsu Yoshioka • Toshiaki Kubota
}

Received: 28 January 2011 /Revised: 6 June 2011 /Accepted: 28 July 2011 / Published online: 20 August 2011

(C) The Author(s) 2011. This article is published with open access at Springerlink.com

\begin{abstract}
Purpose Transforming growth factor (TGF)- $\beta$ is a key mediator of proliferative vitreoretinopathy, but the cellular mechanisms by which TGF- $\beta$ induces extracellular matrix protein (ECM) synthesis are not fully understood. This study examined whether the PI3K/Akt pathway is involved in TGF- $\beta 2$-induced collagen expression in human retinal pigment epithelial cells.

Methods Human retinal pigment epithelial cells ARPE-19 were cultured and stimulated with TGF- $\beta 2$. The role of the PI3K/Akt pathway was evaluated using the biochemical inhibitor, wortmannin. The effect of wortmannin on the expression of type I collagen mRNA (COL1A1, COL1A2) induced by TGF- $\beta 2$ was evaluated by real-time RT-PCR. The effect of wortmannin on the synthesis of type I collagen induced by TGF- $\beta 2$ was assessed by an immunocytochemical analysis with anti-type I collagen antibody. Luciferase reporter assays were performed to examine the effect of wortmannin on the transcriptional activities of
\end{abstract}

\footnotetext{
K. Yokoyama $\cdot$ K. Kimoto $(\bowtie) \cdot$ K. Nakatsuka $\cdot$ T. Kubota Department of Ophthalmology, Faculty of Medicine, Oita University,

Hasama-machi, Yufu-shi,

Oita 879-5593, Japan

e-mail: kimotok@oita-u.ac.jp

Y. Itoh

Kyorin Eye Center, Kyorin University School of Medicine, Mitaka, Tokyo, Japan

N. Matsuo $\cdot$ H. Yoshioka

Department of Matrix Medicine, Faculty of Medicine,

Oita University,

Hasama-machi, Yufu-shi,

Oita 879-5593, Japan
}

COL1A2. A luciferase assay using a mutation construct of the Smad binding site in COL1A2 promoter (Smad-mut/Luc) was also performed to examine the crosstalk between the Smad pathway and the PI3K/Akt pathway. The effects of wortmannin on the transcriptional activity of Smad3 were also examined using CAGA12-Luc. Moreover, the effect of wortmannin on TGF- $\beta 2$-induced Smad7 mRNA expression was evaluated.

Results The biochemical blockade of PI3K/Akt activation inhibited TGF- $\beta 2$-induced type I collagen mRNA expression and type I collagen synthesis. The blockade of PI3K/Akt pathway inhibited the increase in COL1A2 promoter activities when induced by TGF- $\beta 2$ and reduced TGF- $\beta 2$ induction of Smad-mut/Luc promoter activity and CAGA12-Luc activity. Moreover, wortmannin increased the TGF- $\beta 2$-induced Smad7 mRNA expression levels.

Conclusions The PI3K/Akt pathway plays a role in relaying the TGF- $\beta 2$ signal to induce type I collagen synthesis in the retinal pigment epithelium through Smaddependent and Smad-independent pathways.

Keywords Retinal pigment epithelium - TGF- $\beta$ - Collagen · PI3K/Akt · Vitreoretinopathy

\section{Introduction}

Proliferative vitreoretinopathy (PVR) is a major cause of the failure of rhegmatogenous retinal detachment surgery $[1,2]$. It is characterized by extracellular matrix (ECM) accumulation in the vitreous cavity and on the inner or outer surfaces of the neural retina [3]. PVR reduces the flexibility of the retina and makes it difficult to reattach the 
retina, and may result in a significant loss of vision. Several studies have shown that retinal pigment epithelial (RPE) cells play a critical role in the pathogenesis of PVR [4-8]. RPE cells are stimulated by various cytokines following rhegmatogenous retinal detachment. These activated RPE cells undergo transformation to fibroblast-like cells, proliferate, migrate through retinal tears and produce ECM to form pathologic membranes $[4,6]$.

The ECM in PVR membranes contains various proteins including collagen, elastin and fibronectin. Type I collagen is the major structural component of the ECM in PVR membranes $[5,6]$. This is a heterotrimer composed of coordinately expressed two $\alpha 1$ chains and one $\alpha 2$ chain. They are encoded by distinct genes, namely COL1A1 and COL1A2 respectively, and their expression is modulated by various cytokines [9].

Transforming growth factor- $\beta$ (TGF- $\beta$ ) is a member of a superfamily of multifunctional cytokines which mediate development, wound repair, and other pathologic processes in many cell types [10]. Three isoforms of TGF- $\beta$, namely TGF- $\beta 1, \beta 2$ and $\beta 3$, are present in mammalian tissues. Although in vitro experiments often elicit similar responses, their in vivo roles and expression are not uniform [11]. TGF- $\beta$ plays a critical role in ECM protein synthesis and accumulation, and is a key mediator of fibrous diseases including pulmonary fibrosis [12], liver cirrhosis [13], and human skin fibrosis [14]. Evidence for high concentrations of TGF- $\beta 2$ in vitreous aspirates from patients with PVR has highlighted its importance in PVR. It should be noted that immunologic assays showed that most TGF- $\beta$ in the vitreous aspirates were TGF- $\beta 2$ isoform, not TGF$\beta 1[15,16]$.

Phosphoinositide 3-kinase (PI3K), which contains p85 catalytic and p110 regulatory subunits, plays a crucial role as a mediator of growth factor signaling, cell proliferation, cell survival, and apoptotic inhibition. The serine/threonine kinase Akt is an important target of PI3K-generated signals. Akt phosphorylates multiple proteins implicated in cell cycle control to ultimately stimulate cell growth [17]. In some cells, including mesangial cells, skin fibroblasts and human lens epithelial cells, the PI3K/Akt signaling pathway plays a role in either the TGF- $\beta$ induction of type I collagen expression or epithelial mesenchymal transition [18-21]. However, the role of the PI3K-Akt pathway in TGF- $\beta$ induced collagen expression has not been fully investigated in human RPE.

We and the other researchers previously showed that Smad, p38 MAPK and RhoA/Rho-kinase pathways mediate the expression of type I collagen induced by TGF- $\beta 2$ in retinal pigment epithelial cells $[11,22,23]$. The current study was conducted to examine whether the PI3K/Akt pathway is involved in the TGF- $\beta 2$-induced collagen expression of RPE cells.

\section{Materials and methods}

\section{Reagents}

Recombinant human TGF- $\beta 2$ was purchased from R\&D Systems (Minneapolis, MN, USA). Wortmannin, a PI3K inhibitor, was purchased from Sigma (St. Louis, MO, USA). Antibodies were purchased from various vendors: anti-PI3K p85 and anti-phospho-PI3K p85 were from Cell Signaling Technology (Beverly, MA, USA). Anti-phospho-Akt, anti-Akt were from SABiosciences (Frederick, MN, USA). Anti-human type I collagen mouse monoclonal antibody was from Southern Biotech (Birmingham, AL, USA). Secondary anti-mouse IgG2b antibody was from Santa Cruz Biotechnology (Santa Cruz, CA, USA). DAPI solution was from DOJNJO Laboratories (Kumamoto, Japan).

\section{Cell culture and stimulation by TGF- $\beta 2$}

The cells of the human retinal pigment epithelial line ARPE-19 were obtained from the American Type Culture Collection (ATCC; Manassas, VA, USA). ARPE-19 is an immortalized, nontransfected cell line that spontaneously arose from cultures of human RPE. Cells were maintained in 1:1 (vol/vol) mixture of Dulbecco's modified Eagle's and Ham's F12 medium (DMEM/F12; ATCC) supplemented with $10 \%$ heat-inactivated fetal bovine serum (FBS; Sanko Junyaku, Tokyo, Japan) and antibiotics (100 U/ml penicillin $\mathrm{G}$ and $100 \mu \mathrm{g} / \mathrm{ml}$ streptomycin sulfate) in a humidified incubator at $37^{\circ} \mathrm{C}$ in $5 \% \mathrm{CO}_{2}$. Cells were used at passage numbers 13 to 18 in the present studies.

The medium was removed from confluent cultures and replaced with serum-free DMEM/F12. After 24 hours of serum starvation, $10 \mathrm{ng} / \mathrm{ml}$ of TGF- $\beta 2$ was added to the medium, and the cultures were incubated another 24 hours for RNA isolation and protein analysis. The cells were preincubated for 30 minutes before treatment with or without exogenous TGF- $\beta 2$ prior to treatment with the $\mathrm{PI} 3 \mathrm{~K}$ inhibitor wortmannin.

\section{Western blot analysis of PI3K p85 activation}

Cells grown to confluence were cultured for $24 \mathrm{~h}$ with serum-free medium, and then were treated with $10 \mathrm{ng} / \mathrm{ml}$ of TGF- $\beta 2$ for different periods of time with or without wortmannin. The cells were washed twice with ice-cold phosphate buffered saline (PBS), then lysed on ice in M-PER Mammalian Protein Extraction Reagent containing protease and phosphatase inhibitors (Pierce, Rockford, IL, USA). Cell extracts were centrifuged at $15,000 \mathrm{~g}$ for $10 \mathrm{~min}$ at $4^{\circ} \mathrm{C}$, supernatants were collected, and the protein content was determined using the BCA Protein Assay Reagent kit 
(Pierce). Fresh cell extracts were prepared in sample buffer (0.125 M Tris-HCl (pH 6.8), 4\% SDS, 20\% glycerol, $0.002 \%$ bromophenol blue, $10 \%$ 2-mercaptoethanol). Samples were resolved by SDS-PAGE and electroblotted onto a polyvinylidene difluoride (PVDF) membrane. Equal loading and appropriate transfer of each lane was confirmed by staining the PVDF membrane with the Ponceau S solution (Sigma). After blocking with a PVDF blocking reagent (TOYOBO, Osaka, Japan) for $1 \mathrm{~h}$ at room temperature, membranes were incubated with an anti-PI3K p85 antibody or anti-phospho-PI3K p85 antibody overnight at $4{ }^{\circ} \mathrm{C}$, followed by incubation with the horseradish peroxidase (HRP)conjugated anti-rabbit IgG for $1 \mathrm{~h}$ at room temperature. The signals were enhanced using a chemiluminescence system (ECL plus; Amersham Pharmacia Biotech, Buckinghamshire, England) and exposed to X-ray film.

Quantification of activation of Akt

Cells were seeded in 96-well plates, incubated in medium containing $10 \%$ FBS and grown to confluence. The medium was changed to serum-free DMEM/F12 for $24 \mathrm{~h}$, followed by incubation in the presence of TGF- $\beta 2(10 \mathrm{ng} / \mathrm{mL})$ for different periods with or without wortmannin. Akt activation by TGF- $\beta 2$ was quantified by using a CASETM kit for Akt according to the manufacturer's instructions (SuperArray Biosciences, Frederick, MD, USA). Cells were fixed with $8 \%$ formaldehyde for $30 \mathrm{~min}$ and processed for ELISA measurements with anti-pS473-Akt or anti-Akt antibodies. The bound antibodies were then detected with anti-mouse acetylcholine esterase conjugate, followed by color development. Absorbance at $450 \mathrm{~nm}$ was determined using a microplate spectrophotometer.

RNA isolation and cDNA synthesis

Total RNA was prepared using a minikit (RNeasy; Qiagen, Valencia, CA, USA). Cells in lysis buffer containing $1 \% \beta$ mercaptoethanol were passed through a separation column (QIA Shredder; Qiagen), and total RNA was obtained according to the manufacturer's protocol. cDNA was produced with a kit (High Capacity cDNA Reverse Transcription Kit; Applied Biosystems), using random hexamers.

\section{Real-time PCR}

Real-time PCR was performed using a sequence-detection system (Prism TM 7300; Applied Biosystems). The sequence-specific primers and probe mixtures for human COL1A1, COL1A2, Smad7 and human GAPDH (used as an internal control gene) were from predeveloped assays (TaqMan ${ }^{\circledR}$ Gene Expression assays; Applied Biosystems).
The thermal cycling conditions included one cycle at $50^{\circ} \mathrm{C}$ for 2 minutes, one cycle at $95^{\circ} \mathrm{C}$ for 10 minutes, and 40 cycles at $95^{\circ} \mathrm{C}$ for 15 seconds and $60^{\circ} \mathrm{C}$ for 1 minute. The relative mRNA expression levels of COL1A1, COL1A2 and Smad7 were normalized against the GAPDH gene from the same RNA preparations, using a comparative threshold cycle method.

\section{Plasmid constructs}

The COL1A2/luciferase (COL1A2/Luc) construct containing the 436-bp sequence of the COL1A2 promoter and the mutated Smad binding consensus sequence in the COL1A2/Luc (Smad-mut/Luc) were used in these experiments. These have been previously described [22]. CAGA12-Luc is a reporter gene containing 12 repeats of the Smad binding element, and was kindly provided by Dr. Christina Stuelten (NIH).

Immunocytochemical analysis

ARPE-19 cells were seeded in the wells of chamber slides (Nunc, Naperville, IL, USA) in DMEM/F12 supplemented with $10 \%$ FBS and grown to subconfluence. The medium was changed to serum-free DMEM/F12 for $24 \mathrm{~h}$, followed by incubation in the presence or absence of $10 \mathrm{ng} / \mathrm{ml}$ of TGF- $\beta 2$, with or without wortmannin, in medium containing $200 \mu \mathrm{M}$ of L-ascorbic acid 2-phosphate (Wako Pure Chemical Industries, Osaka, Japan). The cells were then fixed in $4 \%$ paraformaldehyde, permeabilized with $0.1 \%$ Triton X-100, then blocked with $0.5 \%$ bovine serum albumin. The specimens were then processed for immunofluorescence staining with a monoclonal anti-human type I collagen antibody (1:200 dilution in phosphate-buffered saline). Cells were then incubated with FITC-conjugated anti-mouse IgG and DAPI for an hour at room temperature, and deposition of the type I collagen in each cell was photographed and analyzed.

Transient transfection and luciferase assays

The transcriptional activity of COL1A2 was determined by transient transfection of ARPE-19 cells. The EndoFree Plasmid Maxi kit (Qiagen) was used to purify the plasmids. ARPE-19 cells were transfected using Effectence Transfection Reagent (Qiagen). Cells were seeded in the plate the day before transfection. Cells were transfected at $60-80 \%$ confluence according to the manufacturer's recommendations. Six hours later, cells were stimulated with or without TGF- $\beta 2(10 \mathrm{ng} / \mathrm{ml})$ in the presence or absence of wortmannin for an additional $24 \mathrm{~h}$. The cells were lysed and assayed using the dual luciferase reporter assay system (Promega). 
Luciferase activities were analyzed using a luminometer (Lumat LB.9507, EG and G, Berthold, Germany). A construct containing renilla luciferase (pRL-TK, Promega) was cotransfected with COL1A2/Luc or Smad-mut/Luc, and used as a control for transfection efficiency. The values were expressed relative to the activity in non-treated cells. CAGA12-Luc was transfected with or without TGF- $\beta 2$ $(10 \mathrm{ng} / \mathrm{ml})$ in the presence or absence of wortmannin to assess the effects of wortmannin on the transcriptional activity of Smad3.

\section{Statistical analysis}

The values represent the means \pm SD of multiple independent tests. The Wilcoxon signed-rank test was used to evaluate any statistical significance between the groups, and $p<0.05$ was considered to be significant.

\section{Results}

\section{Effect of TGF- $\beta 2$ on PI3K/Akt activation}

We first examined the expression levels of phospho-PI3K and phospho-Akt proteins expression in ARPE-19 cells treated with exogenous TGF- $\beta 2(10 \mathrm{ng} / \mathrm{ml})$ by a Western analysis and ELISA. The anti-phospho-PI3K p 85 and antiphospho-Akt antibodies specifically detects the phosphorylated forms of PI3K p85 and Akt respectively, whereas the anti-PI3K p85 and anti-Akt antibody detects total PI3K p85 or Akt protein. TGF- $\beta 2$ increased the phosphorylation of PI3K p85 and Akt within 5 minutes after stimulation, and those activations persisted for 24 hours. Preincubation of ARPE-19 with wortmannin blocked the TGF- $\beta 2$-induced Akt activation (Fig. 1).

Effect of wortmannin on the type I collagen mRNA expression by TGF- $\beta 2$

Exogenous TGF- $\beta 2$ induces PI3K/Akt phosphorylation in ARPE-19 cells. The effect of wortmannin $(10 \mu \mathrm{M})$ on TGF- $\beta 2(10 \mathrm{ng} / \mathrm{ml})$ induction of type I collagen mRNA (COL1A1 and COL1A2) expression was evaluated by realtime RT-PCR. Cells expressed a basal level of type I collagen genes, and type I collagen mRNA expression increased markedly following treatment with exogenous TGF- 32 [18]. Preincubation of ARPE-19 with wortmannin significantly reduced the expression of type I collagen mRNA (Fig. 2). Inhibitor treatment had very little effect on the basal levels of type I collagen mRNA expression. These results indicated that the PI3K/Akt pathway mediates TGF$\beta 2$-induced expression of COL1A1 and COL1A2 mRNAs.

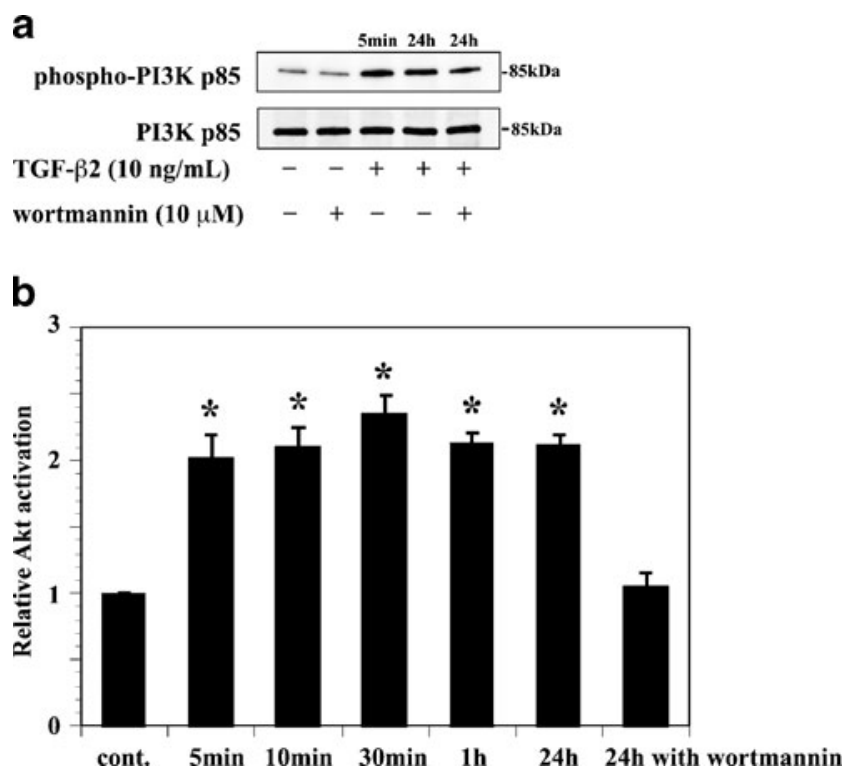

Fig. 1 PI3K p85 and Akt activation induced by TGF- $\beta 2$ in ARPE-19 cells. a PI3K p85 activation: lysates from cells pretreated with or without wortmannin $(10 \mu \mathrm{M})$ and incubated in the presence or absence of TGF- $\beta 2(10 \mathrm{ng} / \mathrm{ml})$ for $5 \mathrm{~min}$ or $24 \mathrm{~h}$. Bands corresponding to the phosphorylated form of PI3K p85 (top) and total PI3K p85 (bottom) were detected. Wortmannin did not inhibit TGF- $\beta 2$-induced PI3K p 85 activation. b Akt activation: lysates from cells incubated in the presence of TGF- $\beta 2$ with or without pretreatment with wortmannin were analyzed using a kit. Wortmannin inhibited TGF- $\beta 2$-induced Akt activation. Data represent the means \pm $\mathrm{SD}$ of three independent experiments. $* P<0.01$, in comparison to no stimulation with TGF- $\beta 2$

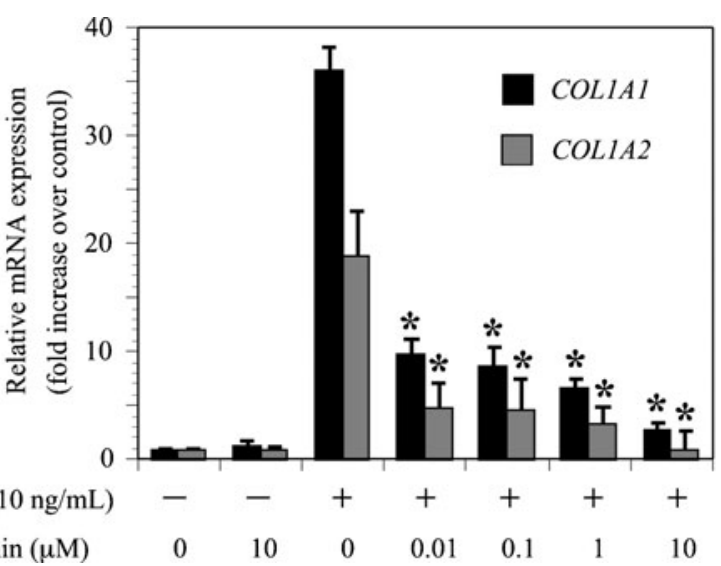

Fig. 2 Effects of wortmannin on TGF- $\beta 2$-induced COL1A1 and COL1A2 mRNA expression. Quiescent cells were pretreated with or without wortmannin and incubated in the presence or absence of TGF$\beta 2(10 \mathrm{ng} / \mathrm{ml})$ for 24 hours. The relative levels of mRNA were normalized against GAPDH from the same cDNA preparation. Values represent the means $\pm \mathrm{SD}$ of three independent experiments. $* P<0.01$, in comparison to stimulation with TGF- $\beta 2$ and without inhibitors 


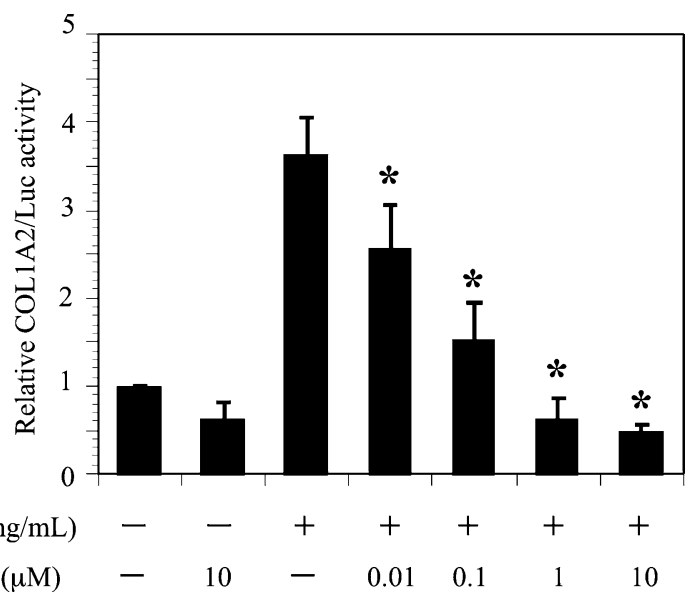

Fig. 3 Effects of wortmannin on TGF- $\beta 2$-induced COL1A2 promoter activity in ARPE-19 cells. Transfected cells were pretreated with or without wortmannin and incubated in the presence or absence of TGF$\beta 2(10 \mathrm{ng} / \mathrm{ml})$ for 24 hours. Results are expressed relative to untreated control cells. Values represent the means $\pm \mathrm{SD}$ of three independent experiments. ${ }^{*} P<0.01$, in comparison to stimulation with TGF- $\beta 2$ and without inhibitors

Effect of wortmannin on the COL1A2/Luc promoter activity induced by TGF- $\beta 2$

The effect of wortmannin on TGF- $\beta 2$ induction of the COL1A2/Luc promoter was investigated in ARPE-19 cells (Fig. 3). Treatment with wortmannin significantly reduced the COL1A2/Luc promoter activity induced by TGF- $\beta 2$.
The inhibitor treatment had little effect on the basal promoter activities of COL1A2/Luc. These findings indicated that the PI3K/Akt pathway is involved in the transcriptional activation of COL1A2 by TGF- $\beta 2$.

Immunocytochemical observation of ARPE-19 treated with wortmannin in the presence of TGF- $\beta 2$

ARPE-19 cells were immunostained to examine whether the expression of type I collagen protein was correlated with the inhibition of gene expression and promoter activity by wortmannin, in the presence or absence of TGF- $\beta 2$. Increased expression of type I collagen was observed in cells treated with TGF- $\beta 2$ in comparison to controls (Fig. $4 \mathrm{a}$ and b). On the other hand, addition of wortmannin to ARPE-19 cells treated with TGF- $\beta 2$ dramatically inhibited the expression of type I collagen (Fig. 4c).

Effect of wortmannin on the Smad-mut/Luc promoter and CAGA12-Luc activity induced by TGF- $\beta 2$

TGF- $\beta 2$ signals from the cell surface to the nucleus are transduced by Smad2,-3 and-4, and phosphorylation of Smad2/3 is crucial for this downstream signaling cascade. Smad protein mediates TGF- $\beta$ signaling and stimulates COL1A2 mRNA expression. Therefore, the role of wortmannin on regulating the mutated Smad binding site construct (Smad-mut/Luc) was evaluated in ARPE-19 cells.
Fig. 4 Wortmannin reduces the production of TGF- $\beta 2$-induced type I collagen in ARPE-19

cells. Cells were preincubated with vehicle or wortmannin (c) for $30 \mathrm{~min}$ and incubated in the absence (a) or presence $(\mathbf{b}, \mathbf{c})$ of TGF- $\beta 2(10 \mathrm{ng} / \mathrm{mL})$ for $24 \mathrm{~h}$. Bar: $100 \mu \mathrm{m}$
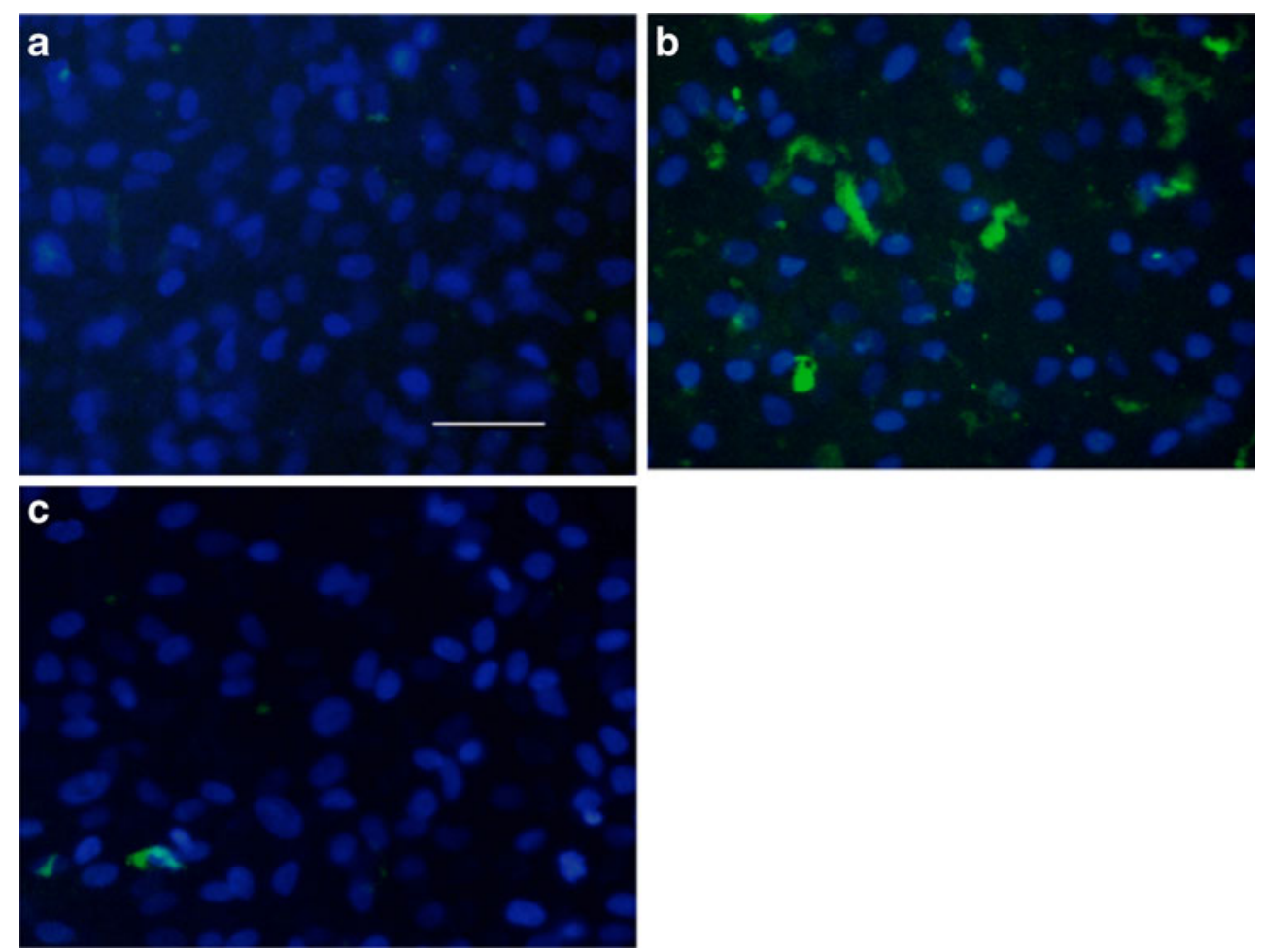
TGF- $\beta 2$ induction of Smad-mut/Luc promoter activity was significantly diminished, in comparison to the activity of COL1A2/Luc (Fig. 5). Moreover, treatment with wortmannin reduced TGF- $\beta 2$ induction of Smad-mut/Luc promoter activity. On the other hand, wortmannin significantly reduced CAGA12-Luc, a reporter gene containing 12 repeats of the Smad binding element, induction by TGF- $\beta 2$ (Fig. 6). These findings indicated that the PI3K/Akt pathway mediates type I collagen expression induced by TGF- $\beta 2$ in ARPE-19 cells through Smad-independent and Smad-dependent pathways.

Effect of wortmannin on the Smad7 mRNA expression induced by TGF- $\beta 2$

Smad7, an inhibitory Smad, is a key regulator of TGF- $\beta$ signaling by negative feedback loop. The effect of wortmannin $(10 \mu \mathrm{M})$ on TGF- $\beta 2(10 \mathrm{ng} / \mathrm{ml})$ induction of Smad7 mRNA expression was evaluated in ARPE-19 by real-time RT-PCR. Preincubation of ARPE-19 with wortmannin increased the expression levels of TGF- $\beta 2$-induced Smad7 mRNA (Fig. 7).

\section{Discussion}

This study examined the role of PI3K/Akt signaling cascades in mediating the effects of TGF- $\beta 2$ on type I collagen synthesis in the human retinal pigment epithelial cell line, ARPE-19. The results suggest that the PI3K/Akt pathway could be involved in TGF- $\beta 2$-induced collagen

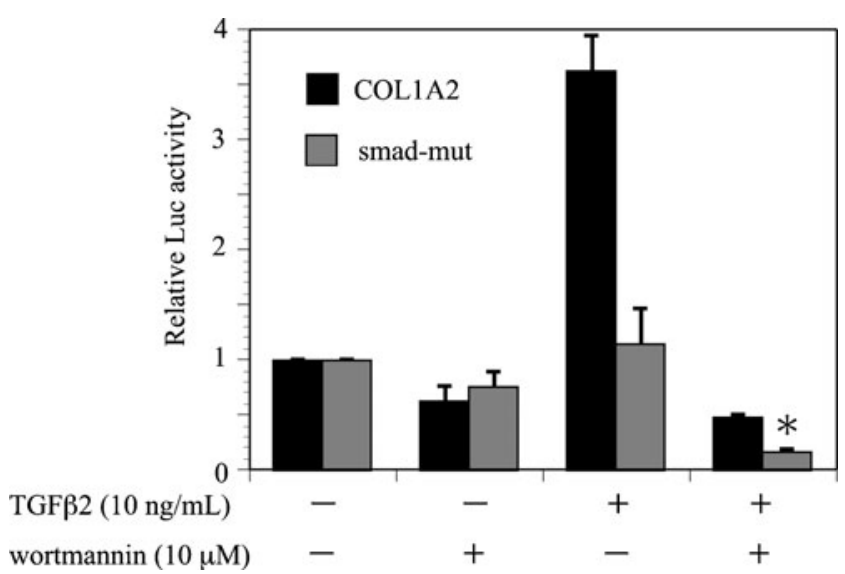

Fig. 5 Effects of wortmannin on TGF- $\beta 2$-induced Smad-mut/Luc promoter activity in ARPE-19 cells. Transfected cells were pretreated with or without wortmannin and incubated in the presence or absence of TGF- $\beta 2(10 \mathrm{ng} / \mathrm{ml})$ for 24 hours. Results are expressed relative to untreated control cells. Values represent the means \pm SD of three independent experiments. ${ }^{*} P<0.01$, in comparison to stimulation with TGF- $\beta 2$ and without inhibitors

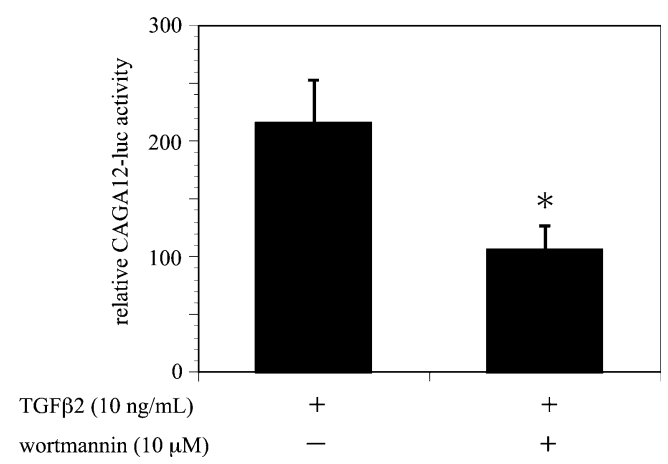

Fig. 6 Effects of wortmannin on TGF- $\beta 2$-induced CAGA12-Luc activity in ARPE-19 cells. Transfected cells were pretreated with or without wortmannin and incubated in the presence or absence of TGF$\beta 2(10 \mathrm{ng} / \mathrm{mL})$ for 24 hours. Results are expressed relative to untreated control cells. Values represent the means $\pm \mathrm{SD}$ of three independent experiments. $* P<0.01$, in comparison to stimulation with TGF- $\beta 2$ and without inhibitors

synthesis in ARPE-19 cells. Treatment with wortmannin, an inhibitor of the PI3K/Akt pathway, significantly reduced mRNA, promoter activity, and the expression of type I collagen protein in response to TGF- $\beta 2$ in ARPE-19. Type I collagen is the major structural component of the extracellular matrix in fibrous disease in the lung [12], liver [13], skin [14], eye [11, 24]. Studies of these diseases have shown that type I collagen synthesis is influenced by various cytokines including platelet-derived growth factor (PDGF) [25], basic fibroblast growth factor (bFGF) [26] and TGF- $\beta$ [27]. In particular, the TGF- $\beta$ family is a key

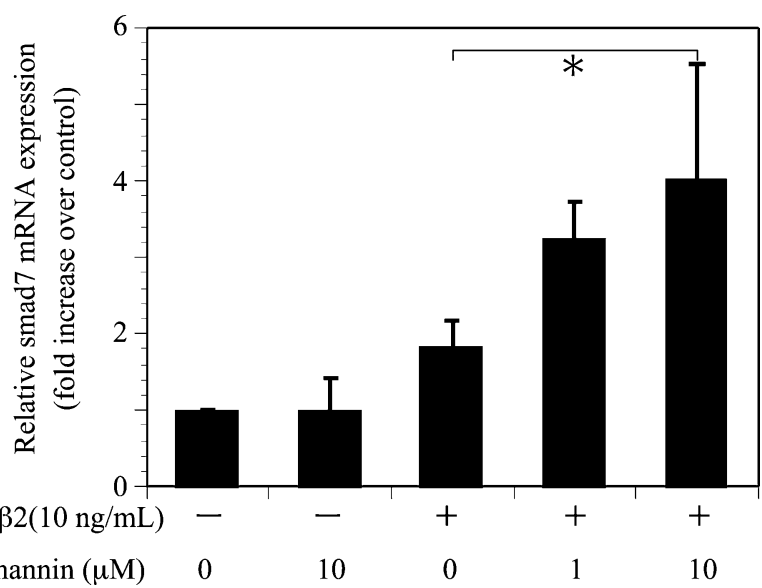

wortmannin $(\mu \mathrm{M}) \quad 0$

Fig. 7 Effects of wortmannin on TGF- $\beta 2$-induced Smad 7 mRNA expression. Quiescent cell were pretreated with or without wortmannin and incubated in the presence or absence of TGF- $\beta 2(10 \mathrm{ng} / \mathrm{ml})$ for 24 hours. The relative levels of mRNA were normalized against GAPDH from the same cDNA preparation. Values represent the means \pm SD of three independent experiments. ${ }^{*} P<0.05$, in comparison to stimulation with TGF- $\beta 2$ and without inhibitors 
modulator of type I collagen synthesis. TGF- $\beta$ is associated with ECM production through different pathways, such as Smads [28-30], p38MAPK [11, 22, 31], and RhoA/Rhokinase $[23,24]$ in some cell types.

A few studies have suggested that TGF- $\beta$ stimulates the PI3K/Akt signaling pathway, which regulates type I collagen expression in some cell types [18-20]. TGF- $\beta 1$ activates Akt, a downstream target of PI3K, in human mesangial cells and dermal fibroblasts. Inhibition of the PI3K abrogates TGF- $\beta 1$-stimulated COL1A2 gene transcription. These results are consistent with the present results with COL1A2 in human retinal pigment epithelial cells.

Smads, the downstream target of TGF- $\beta$, are the major transduction pathways between cell surface TGF- $\beta$ receptors and gene promoters $[32,33]$.

Receptor-regulated Smad2 and Smad3 are activated and phosphorylated by the activated receptor complex composed of type I and type II serine/threonine kinase receptors. Smad2 and Smad3 then form a heterodimer complex with a common mediator, Smad4. The hetero oligomeric Smad2/3/4 complex translocates into the nucleus, where it binds promoters, and mediates transcription of target genes $[32,33]$. Smads are influenced by multiple signaling pathways including p38MAPK [11, 22] and Rho [23] in ARPE-19. The PI3K/Akt pathway mediates Smad3 activity in some cell types $[18,20]$. The activation of PI3K pathway by TGF- $\beta 1$ enhances Smad3 transcriptional activity in human mesangial cells, leading to increased collagen I expression. However, activation of the PI3K pathway alone is not sufficient to increase COL1A2 gene expression. This report suggests that PI3K can modulate type I collagen expression only when the Smad proteins also are activated [18]. The current study evaluated the effects of wortmannin on the transcriptional activity of Smad3 using CAGA12-Luc. Wortmannin significantly reduced the TGF- $\beta 2$-induced activity of CAGA12-Luc. This finding indicated that the PI3K/Akt pathway mediates the induction of COL1A2 gene expression by TGF- $\beta 2$ in ARPE-19 cells via Smad3 transcriptional activity. However, treatment with wortmannin also significantly reduced TGF- $\beta 2$ induction of the Smad-mut/Luc promoter activity. This indicated that the PI3K/Akt pathway mediates the COL1A2 gene expression by TGF- $\beta 2$ in ARPE-19 cells without Smad3 activity as well. So the PI3K/Akt pathway probably mediates type I collagen expression by TGF- $\beta 2$ in ARPE-19 cells through Smad-dependent and Smad-independent pathways.

Smad7 is the inhibitory Smad, which inhibits phosphorylation of $\mathrm{Smad} 2 / 3$ and thus attenuates nuclear translocation of the Smad complex [34]. Several studies demonstrate that overexpressing Smad7 attenuates collagen synthesis induced by TGF- $\beta 1$ [35]. Therefore, introducing Smad7 is of therapeutic value in pathological tissue fibrosis. With respect to the role of Smad7 in PVR, Smad7 gene transfer suppresses fibrogenic responses to TGF- $\beta 2$ by RPE in vitro and in vivo [36]. The current study showed that inhibition of the PI3K/Akt pathway with wortmannin increases Smad7 mRNA expression in ARPE-19 cells. Negative modulation of Smad3 phosphorylation by Smad7 may contribute to the downregulation of collagen production in ARPE-19 cells and inhibition of the PI3K/Akt pathway may induce Smad7 upregulation.

Several reports have indicated the importance of the PI3K/Akt pathway in pathogenesis of PVR. Inhibition of the PI3K/Akt pathway regulates monocyte chemotactic protein (MCP)-1 in human RPE cells, which is detected in the vitreous in PVR [37]. Moreover, blocking PI3K inhibits the collagen gel contraction induced by PDGF [38]. The current study showed that inhibition of the PI3K/Akt pathway suppressed the TGF- $\beta 2$-induced type I collagen expression in human retinal pigment epithelial cells. The PI3K/Akt pathway may therefore be a new therapeutic target for treating PVR.

The limitations of our studies are as follows. First, our studies were performed in RPE culture on plastic plates; this condition does not duplicate the microenvironment that is present in vivo. Therefore, the role of the PI3K/Akt pathway should be further investigated in PVR animal models. Next, we used wortmannin as an inhibitor of the PI3K/Akt pathway. Although many published articles consider it a specific inhibitor of PI3K, wortmannin also inhibits the MAPK pathway independent of its effects on PI3K [39-41]. This is of special concern, as all experiments were built on the use of this chemical. Further experiments should thus be done to determine whether wortmannin inhibits another TGF- $\beta 2$-induced signal pathway in RPE.

We previously showed that the inhibition of the TGF$\beta 2 /$ non-Smad signaling pathway, including p38MAPK [22] and RhoA/Rho-kinase [23], suppresses the expression of type I collagen induced by TGF- $\beta 2$ in RPE. We have herein shown that the PI $3 \mathrm{~K} / \mathrm{Akt}$ pathway is also involved in TGF- $\beta 2$-induced type I collagen synthesis in RPE. It is therefore necessary to further analyze the cross-talk between p38MAPK and RhoA/Rho-kinase and PI3K/Akt in relaying the TGF- $\beta 2$ signal to type I collagen production in RPE.

Acknowledgements This study was supported by Grants-in-Aid for Scientific Research from the Ministry of Education, Culture, Sports, Science and Technology of Japan.

Declaration of interest The authors report no conflicts of interest. The authors alone are responsible for the content and writing of the paper. 
Open Access This article is distributed under the terms of the Creative Commons Attribution Noncommercial License which permits any noncommercial use, distribution, and reproduction in any medium, provided the original author(s) and source are credited.

\section{References}

1. Machemer R (1988) Proliferative vitreoretinopathy (PVR): a personal account of its pathogenesis and treatment. Invest Ophthalmol Vis Sci 29:1771-1783

2. Pastor JC (1998) Proliferative vitreoretinopathy: an overview. Surv Ophthalmol 43:3-18

3. Jerdan JA, Peose JS, Michels RG, Hayashi H, de Bustros S, Sebag M, Glaser BM (1989) Proliferative vitreoretinopathy membranes: an immunohistochemical study. Ophthalmology 96:801-810

4. Machemer R, Van Horn D, Aaberg TM (1978) Pigment epithelial proliferation in human retinal detachment with massive periretinal proliferation. Am J Ophthalmol 85:181-191

5. Scheiffarth OF, Kampik A, Günther H, von der Mark K (1988) Proteins of the extracellular matrix in vitreoretinal membranes. Graefes Arch Clin Exp Ophthalmol 226:357-361

6. Hiscott P, Sheridan C, Magee RM, Grierson I (1999) Matrix and the retinal pigment epithelium in proliferative retinal disease. Prog Retin Eye Res 18:167-190

7. Raymond MC, Thompson JT (1990) RPE-mediated collagen gel contraction. Inhibition by colchicine and stimulation by TGF-beta. Invest Ophthalmol Vis Sci 31:1079-1086

8. Grisanti S, Guidry C (1995) Transdifferentiation of retinal pigment epithelial cells from epithelial to mesenchymal phenotype. Invest Ophthalmol Vis Sci 36:391-405

9. Slack JL, Liska DJ, Bornstein P (1993) Regulation of expression of the type I collagen gene. Am J Med Genet 45:140-151

10. Border WA, Noble NA (1994) Transforming growth factor beta in tissue fibrosis. N Engl J Med 331:1286-1292

11. Saika S (2006) TGF-beta pathobiology in the eye. Lab Invest 86:106-115

12. Krupsky M, Fine A, Kuang PP, Berk JL, Goldstein RH (1996) Regulation of type I collagen production by insulin and transforming growth factor-beta in human lung fibroblasts. Connect Tissue Res 34:53-62

13. Liu X, Hu H, Yin JQ (2006) Therapeutic strategies against TGFbeta signaling pathway in hepatic fibrosis. Liver Int 26:8-22

14. Chen SJ, Yuan W, Mori Y, Levenson A, Trojanowska M, Varga J (1999) Stimulation of type I collagen transcription in human skin fibroblasts by TGF-beta: involvement of Smad3. J Invest Dermatol 112:49-57

15. Connor TB Jr, Roberts AB, Sporn MB, Danielpour D, Dart LL, Michels RG, de Bustros S, Enger C, Kato H, Lansing M, Hayashi $\mathrm{H}$, Glaser BM (1989) Correlation of fibrosis and transforming growth factor-beta type 2 levels in the eye. J Clin Invest 83:1661-1666

16. Pfeffer BA, Flanders KC, Gúerin CJ, Danielpour D, Anderson DH (1994) Transforming growth factor-beta 2 is the predominant isoform in the neural retina, retinal pigment epithelium-choroid and vitreous of the monkey eye. Exp Eye Res 59:323-333

17. Cantley LC (2002) The Phosphoinositide 3-kinase pathway. Science 296:1655-1657

18. Runyan CE, Schnaper HW, Poncelet AC (2004) The phosphatidylinositol 3-kinase/Akt pathway enhances Smad3-stimulated mesangial cell collagen I expression in response to transforming growth factor-beta 1. J Biol Chem 279:2632-2639

19. Hubchak SC, Sparks EE, Hayashida T, Schnaper HW (2009) Rac1 promotes TGF- $\beta$-stimulated mesangial cell type I collagen expression through a PI3K/Akt-dependent mechanism. Am J Physiol Renal Physiol 297:F1316-F1323

20. Asano Y, Ihn H, Yamane K, Jinnin M, Mimura Y, Tamaki K (2004) Phosphatidylinositol 3-kinase is involved in alpha2(I) collagen gene expression in normal and scleroderma fibroblasts. J Immunol 172:7123-7135

21. Yao K, Ye PP, Tang XJ, Shen Tu XC (2008) Involvement of PI3K/ Akt pathway in TGF- $\beta 2$-mediated epithelial mesenchymal transition in human lens epithelial cells. Ophthalmic Res 40:69-76

22. Kimoto K, Nakatsuka K, Matsuo N, Yoshioka H (2004) p38 MAPK mediates the expression of type I collagen induced by TGF-beta 2 in human retinal pigment epithelial cells ARPE-19. Invest Ophthalmol Vis Sci 45:2431-2437

23. Itoh Y, Kimoto K, Imaizumi M, Nakatsuka K (2007) Inhibition of RhoA/Rho-kinase pathway suppresses the expression of type I collagen induced by TGF-beta 2 in human retinal pigment epithelial cells. Exp Eye Res 84:464-472

24. Kita T, Hata Y, Arita R, Kawahara S, Miura M, Nakao S, Mochizuki Y, Enaida H, Goto Y, Shimokawa H, Hafezi-Moghadam A, Ishibashi $\mathrm{T}$ (2008) Role of TGF-beta in proliferative vitreoretinal diseases and ROCK as a therapeutic target. Proc Natl Acad Sci USA 45:17504-17509

25. Cassidy L, Barry P, Shaw C, Duffy J, Kennedy S (1998) Platelet derived growth factor and fibroblast growth factor basic levels in the vitreous of patients with vitreo-retinal disorders. $\mathrm{Br} \mathrm{J}$ Ophthalmol 82:181-185

26. Kon CH, Occleston NL, Aylward GW, Khaw PT (1999) Expression of vitreous cytokines in proliferative vitreoretinopathy: a prospective study. Invest Ophthalmol Vis Sci 40:705-712

27. Ignotz RA, Endo T, Massagué J (1987) Regulation of fibronectin and type I collagen mRNA levels by transforming growth factor-beta. J Biol Chem 262:6443-6446

28. Derynck R, Zhang YE (2003) Smad-dependent and Smadindependent pathways in TGF-beta family signaling. Nature 425:577-584

29. Tsukada S, Westwick JK, Ikejima K, Sato N, Rippe RA (2005) SMAD and p38MAPK signaling pathways independently regulate alpha (I) collagen gene expression in unstimulated and transforming growth factor-beta-stimulated hepatic stellate cells. J Biol Chem 280:10055-10064

30. Poncelet AC, de Caestecker MP, Schnaper HW (1999) The transforming growth factor-beta/SMAD signaling pathway is present and functional in human mesangial cells. Kidney Int $56: 1354-1365$

31. Sato M, Shegogue D, Gore EA, Smith EA, McDermott PJ, Trojanowska M (2002) Role of p38 MAPK in transforming growth factor beta stimulation of collagen production by scleroderma and healthy dermal fibroblasts. J Invest Dermatol 118:704-711

32. Heldin CH, Miyazono K, Dijke P (1997) TGF-beta signaling from cell membrane to nucleus through Smad proteins. Nature 390:465-471

33. Derynck R, Zang Y, Feng XH (1998) Smad: transcriptional activators of TGF-beta responses. Cell 95:737-740

34. Nakao A, Afrakhte M, Morén A, Nakayama T, Christian JL, Heuchel R, Itoh S, Kawabata M, Heldin NE, Heldin CH, ten Dijke P (1997) Identification of Smad7, a TGFbeta-inducible antagonist of TGF-beta signaling. Nature 389:631-635

35. Wang B, Omar A, Angelovska T, Drobic V, Rattan SG, Jones SC, Dixon IM (2007) Regulation of collagen synthesis by inhibitory Smad7 in cardiac myofibroblasts. Am J Physiol Heart Circ Physiol 293:1282-1290

36. Saika S, Yamanaka O, Nishikawa-Ishida I, Kitano A, Flanders KC, Okada Y, Ohnishi Y, Nakajima Y, Ikeda K (2007) Effect of Smad7 gene overexpression on transforming growth factor beta- 
induced retinal pigment fibrosis in a proliferative vitreoretinopathy mouse model. Arch Ophthalmol 125:647-654

37. Bian ZM, Elner SG, Yoshida A, Elner VM (2004) Differential involvement of phosphoinositide 3-kinase/Akt in human RPE MCP-1 and IL-8 expression. Invest Ophthalmol Vis Sci 45:1887-1896

38. Bando H, Ikuno Y, Hori Y, Sayanagi K, Tano Y (2006) Mitogenactivated protein kinase (MAPK) and phosphatidylinositol-3 kinase (PI3K) pathways differently regulate retinal pigment epithelial cellmediated collagen gel contraction. Exp Eye Res 82:529-537

39. Cross MJ, Stewart A, Hodgkin MN, Kerr DJ, Wakelam MJ (1995) Wortmannin and its structural analogue demethoxyviridin inhibit stimulated phospholipase A2 activity in Swiss $3 \mathrm{~T} 3$ cells. Wortmannin is not a specific inhibitor of phosphatidylinositol 3-kinase. J Biol Chem 270:25352-25355

40. Ferby I, Waga I, Kume K, Sakanaka C, Shimizu T (1996) PAF-induced MAPK activation is inhibited by wortmannin in neutrophils and macrophages. Adv Exp Med Biol 416: 321-326

41. Ferby IM, Waga I, Hoshino M, Kume K, Shimizu T (1996) Wortmannin inhibits mitogen-activated protein kinase activation by platelet-activating factor through a mechanism independent of p85/p110-type phosphatidylinositol 3-kinase. J Biol Chem 271:11684-11688 